http://dx.doi.org/10.1016/i.aquaculture.2010.09.001

(c) 2010 Elsevier Ltd All rights reserved.

\title{
Anaesthesia and gonad sampling in the European flat oyster (Ostrea edulis)
}

Marc Suquet ${ }^{\mathrm{a},{ }^{*}}$, Ricardo Gonzales Araya ${ }^{\mathrm{a}}$, Luc Lebrun ${ }^{\mathrm{a}}$, Isabelle Queau ${ }^{\mathrm{a}}$, Christian Mingant ${ }^{\mathrm{a}}$ and René Robert $^{a}$

a Ifremer, Département PFOM, Station Expérimentale d'Argenton, 11 presqu'île du vivier, 29840 Argenton, France

*: Corresponding author : M. Suquet, email address: Marc.Suquet@ifremer.fr

\begin{abstract}
:
Controlled reproduction of the European flat oyster requires the development of tools adapted to this species, including a practical anaesthesia and gonad sampling protocol to facilitate sex determination and the verification of gametogenesis. Three replicate groups of 10 oysters (mean weight \pm SD: $29.9 \pm 8.5 \mathrm{~g}$ ) were anaesthetised in $5 \mathrm{~L}$ containers using magnesium chloride designed either for laboratory (Flucka $\AA$ ) or agricultural (Dead Sea Work ${ }^{\circledR}$ : DSW) use, at two concentrations (50 or $\left.72 \mathrm{~g} \mathrm{~L}^{-1}\right)$. No significant differences were observed in the percentages of oysters anaesthetised or subsequent oyster mortality with the different anaesthetics or concentrations, but increasing water temperature from 14.9 to $18.8^{\circ} \mathrm{C}$ significantly increased the number of oysters anaesthetised after $3 \mathrm{~h}$. Increasing anaesthesia duration from 1 to $22 \mathrm{~h}$ significantly increased the percentage of oysters anaesthetised but did not affect subsequent oyster mortality. Gonad sampling of anaesthetised oysters did not increase oyster mortality either. A reliable anaesthesia protocol was, therefore, defined using $50 \mathrm{~g} \mathrm{~L}^{-1} \mathrm{DSW}{ }^{\circledR}$ magnesium chloride for a 2 to $3 \mathrm{~h}$ duration. This protocol was validated by monthly anaesthesia and gonad sampling on the same oysters over a three month period, during which a percentage of $95 \pm 2 \%$ anaesthetised oysters was observed. Compared with controls (oysters that were neither anaesthetised nor sampled), oyster mortality of monthly anaesthetised batches showed no significant increase.
\end{abstract}

Keywords: Oyster; Ostrea edulis; Anaesthesia; Magnesium chloride; Gonad sampling 


\section{Introduction}

Aquaculture production of the endemic European flat oyster Ostrea edulis decreased from 30000 tonnes in 1961 to 6500 tonnes in 2007 (FAO, 2009) due to two parasites (Marteilia refringens and Bonamia oestrea) that caused a sharp decline in its survival, especially in France (Hegaret and Mazurie, 2005). The selection of resistant individuals has provided a means of improving oyster survival (Naciri-Graven et al., 1998), and thus offered a new opportunity for European flat oyster farming. Hatchery techniques, invaluable for the production of selected resistant lines, have been developed for the species, but adapted tools are still required to improve the control of its reproduction.

Anaesthesia is widely used in aquaculture to facilitate tissue biopsies and gametogenesis studies. In bivalves, tissue sampling often relies on destructive methods, since the shell has to be removed to obtain tissue samples. A reliable anaesthesia and tissue sampling protocol for European flat oyster would enable experiments to be conducted without sacrificing animals, and therefore also allow successive samplings of the same individual. This would facilitate descriptive studies such as those on gametogenesis, while avoiding inter-population variations of the results observed during successive samplings using a destructive method. Furthermore, avoiding oyster sacrifice in aquaculture is particularly valuable for selected animals.

Magnesium chloride has been used successfully to induce anaesthesia in the scallop Pecten fumatus (Heasman et al., 1995), Sydney rock oyster Saccostrea glomerata (Butt et al., 2008) and Pacific oyster Crassostrea gigas (Namba et al., 1995), with low subsequent mortality. In Pacific oyster, the use of agricultural magnesium chloride was found to be just as effective as a laboratory brand, but considerably less expensive (Suquet et al., 2009).

The examination of flat oyster reproductive development requires the development of tools adapted to this species, including a practical anaesthesia and tissue sampling protocol that would enable both sex determination and gametogenesis description. Some elements of such a protocol have already been published (Culloty and Mulcahy, 1992), showing that magnesium chloride induces rapid anaesthesia and recovery of flat oysters. However, variations in results due to differences in anaesthesia conditions were not fully documented in this study. There remained a need to examine the effects of different types of magnesium chloride used, anaesthetic concentration, duration of anaesthetic treatment, oyster weight, water temperature and effects of gonad sampling on subsequent oyster survival. A detailed examination of these parameters under controlled conditions would help to establish a practical anaesthesia and sampling protocol for flat oyster.

Preliminary experiments conducted in our laboratory showed that adding microalgae with the magnesium chloride treatment, starving oysters before treatment or modifying light intensity, had no significant effect on anaesthesia success.

\section{Materials and methods}

20-month-old flat oysters (mean weight \pm SD: $29.9 \pm 8.5 \mathrm{~g}$ ) were transferred from North Brittany (France) to the Argenton experimental hatchery (west Brittany). These oysters were maintained in flow-through seawater tanks at $19{ }^{\circ} \mathrm{C}$ and fed daily according to Chavez-Villalba et al. (2002). 
The standard anaesthesia conditions used, unless otherwise stated, were three replicate groups of 10 oysters, each anaesthetised in $5 \mathrm{~L}$ containers using $50 \mathrm{~g} \mathrm{~L}^{-}$ 1 magnesium chloride designed for agricultural purposes (DSW: Dead Sea Work ${ }^{\circledR}$, Israel: $\mathrm{MgCl}_{2}: 46$ to $48 \%$ ) dissolved in a mixture of fresh water ( $3 \mathrm{~L}$ ) and seawater $(2 \mathrm{~L})$ to maintain salinity. Water temperature was maintained at $19{ }^{\circ} \mathrm{C}$. After $3 \mathrm{~h}$ in the anaesthetic solution, the number of anaesthetised oysters was assessed. Oysters were considered as anaesthetised if shell closure was not observed after three successive pressures on their valves. Following the anaesthetic treatment, oysters were returned to clean seawater and their survival was monitored for one week. Six experiments were conducted during the present study; details and differences from the standard conditions are listed below. Each experiment included at least three control groups $(3 \times 10$ non anaesthetised oysters). When supplementary controls were added, these are detailed below for the appropriate experiments.

Magnesium chloride: source and concentration

Two types of magnesium chloride were used, the first designed for laboratory use (Flucka $^{\circledR}$, Czech Republic) and the second for agriculture use (DSW ${ }^{\circledR}$ ). Each type was tested at two concentrations (50 and $72 \mathrm{~g} \mathrm{~L}^{-1}$ ). To maintain salinity, the highest salt concentration was diluted in fresh water.

\section{Water temperature and oyster weight}

To determine the effect of water temperature, groups of oysters were anaesthetised at $14.9 \pm 0.2{ }^{\circ} \mathrm{C}$ or $18.8 \pm 0.2{ }^{\circ} \mathrm{C}$. Water temperature was maintained using thermo-baths. The effect of oyster weight was studied by exposing groups of oysters with significantly $(F=212.561$, d.f. $=1, P<0.001)$ different mean weight $(19.2 \pm 4.2 \mathrm{~g}$ and $38.3 \pm 5.9 \mathrm{~g})$ to the anaesthetic.

\section{Anaesthesia duration and gonad sampling}

Groups of oysters were left in anaesthetic solution for $1 \mathrm{~h}, 2 \mathrm{~h}, 3 \mathrm{~h}, 5 \mathrm{~h}$ or $22 \mathrm{~h}$. Oyster valve opening was measured using a calliper rule and expressed as the opening rate: (valve opening/shell length) $\times 100$. At the end of anaesthesia (the period the animals were left in the solution), the percentage of oysters that had recovered (those presenting closed valves) was assessed as a function of the time they had spent in clean seawater. Oyster gonads of anesthetised animals were sampled using a $1 \mathrm{ml}$ syringe and needle $(0.6 \times 30 \mathrm{~mm}, 23$ gauge $)$. Survival was then monitored compared with two control groups (control group 1: oysters were neither anaesthetised and nor sampled, control group 2: oysters were anaesthetised but not sampled).

Method validation: oyster survival during a three month period with repeated anaesthesia and sampling

The protocol chosen in the present work was validated by studying the effect of repeated monthly anaesthesia and gonad sampling over a three month period (four samplings in all) on the overall survival of flat oysters. 


\section{Statistical analysis}

Data are presented as mean \pm SD. For each experiment, the percentage of anaesthetised oysters and percentage oyster survival one week following anaesthesia were recorded. The controls were excluded from these statistics since no oysters in these groups were anaesthetised and there was no mortality during the week of monitoring. On the other hand, controls were included in the analysis for the final validation experiment, since mortality was observed in these groups during the three month experimental period. After angular transformation, percentages were compared using one way ANOVA. When the results were significant, a Tukey a posteriori test was used to compare treatments.

\section{Results}

No significant differences $(F=3.388$, d.f. $=4)$ were found in the percentages of anaesthetised oysters or in the levels of oyster mortality $(F=0.795$, d.f. $=4)$ between the treatments made with the different types of magnesium chloride (laboratory vs. agricultural) or at the different concentrations (Table 1). In contrast, the number of oysters anaesthetised was significantly lower $(\mathrm{F}=$ 24.252 , d.f. $=1, P<0.01)$ at $14.9^{\circ} \mathrm{C}(50 \pm 10 \%)$ compared to $18.8{ }^{\circ} \mathrm{C}(83 \pm 6 \%)$, although there was no effect on oyster mortality $(F=0.500$, d.f. $=1)$. Flat oyster weight had no significant effect either on the number of oysters anaesthetised (19.2 g oysters: $93 \pm 12 \%$ and 38.3 g oysters: $77 \pm 23 \%$; $F=2.167$, d.f. $=1$ ) or on oyster survival (no mortality was observed).

Increasing treatment duration from 1 to $22 \mathrm{~h}$ significantly increased the percentage of anaesthetised oysters $(F=5.085$, d.f. $=4, P<0.05), 100 \%$ oysters opened in the longest treatment duration, but no effect $(F=0.500$, d.f. $=4)$ was observed on subsequent oyster mortality (Fig. 1A). Furthermore, increasing treatment duration from 1 to $5 \mathrm{~h}$ significantly increased flat oyster valve opening rate $(F=11.795$, d.f. $=4, P<0.001$, Fig. $1 B)$, thus facilitating tissue biopsy. However, increasing flat oyster anaesthesia duration from $1 \mathrm{~h}$ to $22 \mathrm{~h}$ did not significantly change the percentage of oysters that recovered as a function of time in clean seawater ( $F=0.720$, d.f. $=20$, Fig. $1 C)$.

Gonad sampling of anaesthetised oysters did not significantly increase ( $F=$ 0.074 , d.f. $=1)$ the mortality observed $(3 \pm 6 \%)$ compared with either of the control groups (no mortality in any group).

A mean percentage of $95 \pm 2 \%$ anaesthetised oysters was observed in the monthly anaesthesia and gonad sampling test made over a three month period in the validation test. This percentage did not vary significantly as a function of anaesthesia rank $(F=0.237$, d.f. $=3)$. Compared to the control oysters that were neither anaesthetised nor sampled (survival: $73.3 \pm 15.3 \%$ ), monthly anaesthesia and gonad sampling did not significantly decrease $(F=3.904$, d.f. $=1)$ oyster survival (53.3 $\pm 5.8 \%)$.

\section{Discussion}

The present protocol complements information from the previous study published by Culloty and Mulcahy (1992) to provide a suitable anaesthesia protocol for European flat oysters: our study led to the selection of an agricultural magnesium 
chloride and examined the effects of water temperature, oyster weight and $\mathrm{MgCl}_{2}$ exposure duration on flat oysters anaesthesia success.

Magnesium chloride has been found to be a suitable anaesthetic for many oyster species such as Pacific oyster (Namba et al., 1995) and European flat oyster (Culloty and Mulcahy, 1992). According to results recorded in Pacific oyster (Suquet et al., 2009), the same magnesium chloride designed for agriculture $\left(D_{S W}{ }^{\circledR}\right)$ is as effective as a laboratory brand but 14 times less expensive.

Raising the water temperature (from 14.9 to $18.8^{\circ} \mathrm{C}$ ) increased the percentage of flat oysters anaesthetised, in agreement with our previous results on Pacific oyster (Suquet et al., 2009) comparing similar temperatures $\left(15.3{ }^{\circ} \mathrm{C}\right.$ and 19.5 ${ }^{\circ} \mathrm{C}$ ) but in contrast to another study on Pacific oysters where the opposite trend was observed with a comparison of cooler temperatures (5 and $15^{\circ} \mathrm{C}$; Namba et al., 1995). Flat oyster weight had no significant effect either on the percentage of oysters anaesthetised or on oyster survival. The size of pearl oysters had also no significant effect on anaesthesia success (Norton et al., 1996).

The present study also provides a method that improves gonad sampling in European flat oysters, as increasing exposure duration to magnesium chloride increases the percentage of anaesthetised oysters and the extent of valve opening, thus facilitating tissue sampling. Furthermore, gonad biopsy did not modify flat oyster survival, as also observed in blacklip pearl oyster (AcostaSalmon and Southgate, 2004). Monthly gonad sampling over a three month period did not increase flat oyster mortality. However, long term effects of anaesthesia on reproduction require further research. Furthermore, the representative aspect of sampling must be studied since Acosta-Salmon and Southgate (2004) demonstrated the effect of needle size on the interpretation of gonad stage.

In conclusion, a protocol for the European flat oyster anaesthesia and sampling was established from this work. Flat oysters can be anaesthetised by maintaining them for 2 to $3 \mathrm{~h}$ in a bath (2/3 freshwater and $1 / 3$ seawater) containing $50 \mathrm{~g} \mathrm{~L}^{-1}$ $\mathrm{DSW}^{\circledR}$ magnesium chloride. Monthly anaesthesia and gonad sampling may be carried out, facilitating descriptive studies of European flat oyster cycles including gametogenesis.

\section{Acknowledgments}

The authors wish to thank R. Brizard (Ifremer) for fruitful discussions on the protocols. Many thanks to $\mathrm{H}$. McCombie-Boudry for corrections to the English. The research leading to these results received funding from the European Community Seventh Framework Programme FRP/2007-2013 under grant agreement $\mathrm{N}^{\circ} 222043$ (SETTLE project).

\section{References}

Acosta-Salmon, H., Southgate, P., 2004. Use of a biopsy technique to obtain gonad tissue from the blacklip oyster Pinctada margaritifera (L.). Aquaculture Res. 35, 93-96.

Butt, D., O'Connor, S.J., Kuchel, R., O'Connor, W.A., Raftos, D.A., 2008.

Effects of the muscle relaxants, magnesium chloride, on the Sydney rock oyster (Saccostrea glomerata). Aquaculture 275, 342-346. 
Chavez-Villalba, J., Pommier, J., Andriamiseza, J., Pouvreau, S., Barret, J., Cochard, J.C., Le Pennec, M., 2002. Broodstock conditioning of the oyster Crassostrea gigas : origin and temperature effects. Aquaculture 214, 115-130. Culloty, S.C., Mulcahy, M.F., 1992. An evaluation of anaesthetics for Ostrea edulis (L.). Aquaculture 107, 249-252.

Heasman, M.P., O'Connor, W.A., Frazer, A.W.J., 1995. Induction of anaesthesia in the commercial scallop, Pecten fumatus Reeve. Aquaculture 131, 231-238. Hegaret, H., Mazurié, J., 2005. Restoration of oyster production in France by introduction of non-native species: History and overview. J. Shellfish Res. 24, 1263.

Naciri-Graven, Y., Martin, A.G., Baud, J.P., Renault, T., Gérard, A., 1998.

Selecting the flat oyster Ostrea edulis (L.) for survival when infected with the parasite Bonamia ostreae. Aquaculture 224, 91-107.

Namba, K., Kobayashi, M., Aida, S., Uematsu, K., Yoshida, M., Kondo, Y., Miyata,Y., 1995. Persistent relaxation of the adductor muscle of oyster Crassostrea gigas induced by magnesium ion. Fish. Sci. 61, 241-244.

Norton, J.H., Dashorst, M., Lansky, T.M., Mayer R.J., 1996. An evaluation of some relaxants for use with pearl oysters. Aquaculture 144, 39-52.

Suquet, M., De Kermoysan G., Gonzalez Araya, R., Queau, I., Lebrun, L., Le Souchu, P., Mingant, C., 2009. Anaesthesia in Pacific oyster, Crassostrea gigas. Aquat. Living Resour. 22, 29-34.

\section{Web reference}

FAO, 2009. http://www.fao.org/fishery/statistics/software/fishstat/en 
Fig. 1. Effect of anaesthesia duration on A: the percentage of anaesthetised oysters and subsequent mortality, B: valve opening, C: recovery as a function of time (Different letters refer to significantly different results within parameter).
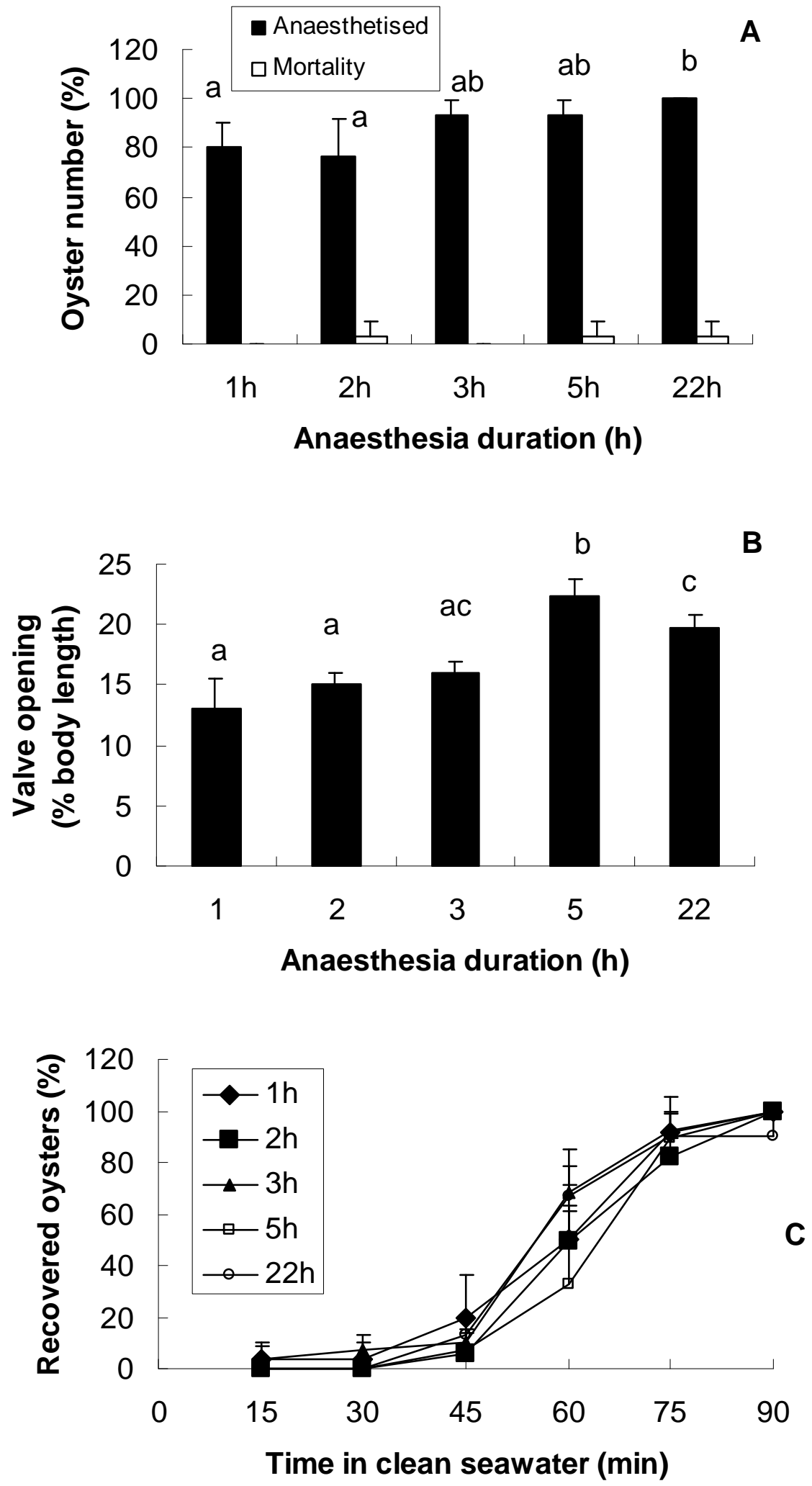


\section{Tables}

Table 1. Effects of anaesthetics and their concentrations on the percentage of anaesthetised oysters and subsequent mortality (means \pm SD).
Magnesium chloride
Anaesthetised oysters
Mortality (\%)

$(\%)$

\begin{tabular}{lcc}
\hline Laboratory $\left(50 \mathrm{~g} \mathrm{~L}^{-1}\right)$ & $70 \pm 27$ & $3 \pm 6$ \\
Laboratory $\left(72 \mathrm{~g} \mathrm{~L}^{-1}\right)$ & $100 \pm 0$ & $7 \pm 6$ \\
Agricultural $\left(50 \mathrm{~g} \mathrm{~L}^{-1}\right)$ & $80 \pm 20$ & $3 \pm 6$ \\
Agricultural $\left(72 \mathrm{~g} \mathrm{~L}^{-1}\right)$ & $87 \pm 15$ & 0 \\
\hline
\end{tabular}

